\title{
A Concise Legal and Economic Review of Sanctions Imposed on Iran by the United States of America and Its Effectiveness on Iranian Authorities*
}

\author{
Mahdis Moharami \\ Department of Law \\ London School of Economics and Political Sciences \\ London, UK
}

\begin{abstract}
The economic impact and legal aspects of the sanctions imposed by the United States of America is summarised here to study its effectiveness as means for persuasion.

\section{INTRODUCTION}

The recent events and new sanctions imposed by the Trump administration on the Iranian economy and his decision to withdraw from JCPOA [1], motivated me to write a review on both the economic and legal sides of the sanctions as well as their effectiveness in restricting Iran's activities in the region. Moreover, the re-imposition of sanctions has had a significant impact on Iranian individuals rather than the government which will be clarified later on in the paper.
\end{abstract}

\section{Sanctions From An Economic Perspective}

To briefly review the economic impact of sanctions on Iran, one might not find a better way but to choose a few relevant economic factors and investigate their fluctuations over a time frame of interest. Firstly, however, a description of the economic sanctions imposed is necessary. According to the US Congressional Research Service [2], there will be a trade ban on Iran for the following industries:

- Oil sale and transaction

- Transshipment and brokering

- Iranian Luxury goods such as carpet and caviar

- Shipping insurance

- Commercial Airline sales

It seems only logical to focus on a few economic factors in this paper. The ones most common citizens are affected by are:

1) Iran's Oil Exportation

2) Iran's Exports and Imports

3) Inflation, Gross Domestic Products (GDP) and Economic Growth

4) Unemployment Rate and the Currency Exchange Rate

Since Iran's economy started to drift away most significantly during Trump's administration, it is sensible to closely follow these economic factors over the past three years (2015-2018). However, due to the lack of data for 2018, the last 10 years have been analysed instead as a basis for predicting the economy.

\section{A. Iran's Oil Exportation}

Interestingly, the large amount of oil in Iran results in the country being dependent on it, making it the biggest source of income for Iran [3]. The trend in Iran's oil export can be seen in Figure 1 .

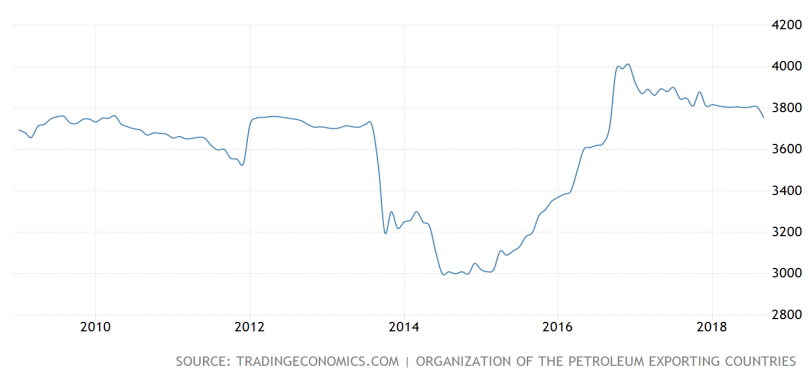

Fig. 1. Islamic Republic of Iran oil export over the last 10 years

Sanctions imposed previously on Iran by the Obama administration decreased Iran's production and oil export by more than $60 \%$ to as low as $1,086,000$ barrels per day in 2014 . The only favourable event for Iran during this period was the high price of oil which clearly peaked in 2014 according to Figure 2. Figures 1 and 2 tell a rather disturbing story of Iran losing over 160 billion dollars of revenue from 2012 to 2015 [4]. JCPOA was signed on July $14^{\text {th }}, 2015$ and the jump in early 2016 along with the sudden increase in Iran's production illustrates a positive consequence of the nuclear deal. It is worth mentioning that despite Iran's quick return to full production capacity, much less revenue was earned due to the historic drop in oil market price. Therefore, with current sanctions reducing Iran's production even more, not a very good fate could be predicted for the country. 


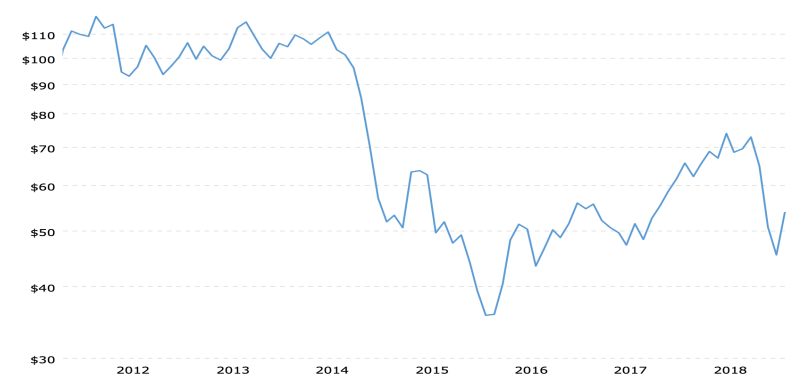

Fig. 2. Price of Oil per barrel over the last 10 years

\section{B. Iran's Exports and Imports}

Since Iran has always been subjected to sanctions which mostly target its oil production, the government started devising policies and regulations for an oil-independent economy. Therefore, a quick review of Iran's oil-independent export, import and balance of trade may give a more precise description of the economy. Figure 3 summarises and predicts the trends in all three factors [5].
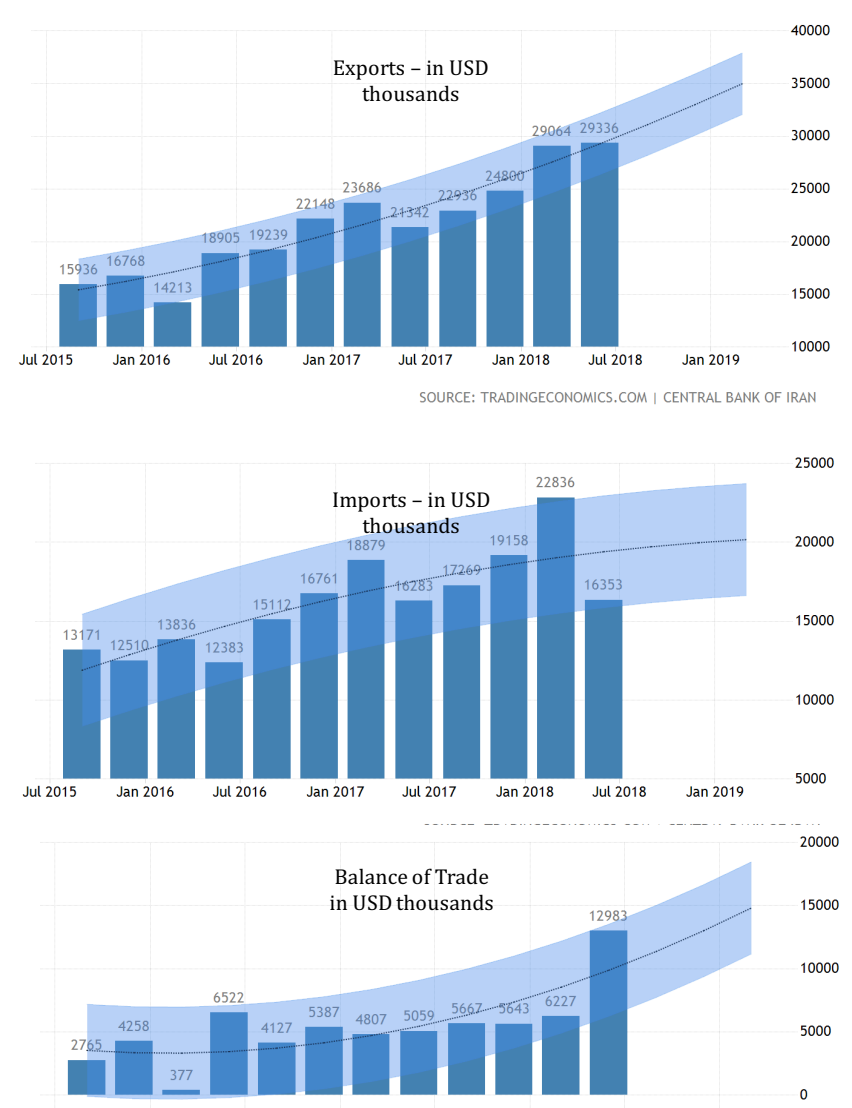

Jul 2015 Jan 2016 Jul $2016 \quad$ Jan 2017 Jul $2017 \quad$ Jan 2018 Jul 2018 Jan $2019 \quad-5000$

SOURCE: TRADINGECONOMICS.COM I CENTRAL BANK OF IRAN

Fig. 3. Iran's exports, Imports and Balance of Trade

Iran's export has increased and is predicted to increase, demonstrating that, to some extent, policies on oil-free economy have paid off. Caution must be taken when analysing imports and the BoT plots since the government has reduced imports significantly in the last 4 or 5 months to decrease the demand for foreign currencies as means to control the chaotic market and drastic drop in the value of Iranian Rial. Hence, the decrease and increase predicted for the imports and BoT respectively do not represent the forced economy of Iran.

\section{Inflation, Gross Domestic Products (GDP) and Economic Growth}

Inflation and GDP are the most relevant factors describing the living standards and the economic pressure under which people are currently living. Fluctuations in Inflation, GDP, GDP per capita and GDP growth rate are all summarised in Figure 4 for a straightforward comparison.
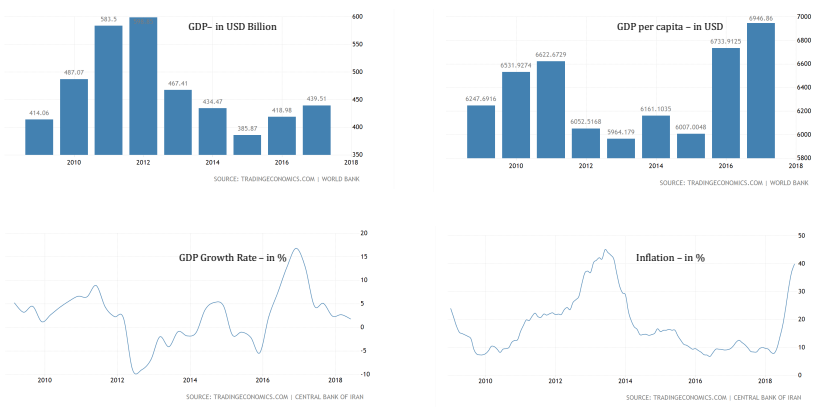

Fig. 4. Iran's GDP, GDP per capita, GDP growth rate and Inflation over the course of the last 10 years

Figure 4 demonstrates how significantly the economic sanctions hit the everyday-life of people in Iran and how the government seem to have lost complete control over the economy during these periods. Iran's GDP and GDP per capita has very sudden drops in all years when the sanctions were tightened. Yet again a sudden and abrupt jump in both GDP and GDP per capita in the 2016-2017 transition period indicates how much Iran's economy is affected by sanctions which could also be seen from the GDP growth rate changing from $-5 \%$ to over $15 \%$ during a 12 -month period. Inflation, as expected, follows the trend and always seem to rise when political tensions are high and new sanctions are imposed. There is one very distinct and alarming difference between Iran's economy today and 8 years ago in 2011. Iran went through previous rounds of sanctions with a very high GDP whereas Iran today has a much lower GDP entering the new rounds of sanctions. This fact, combined with a peak inflation rate, could possibly describe the few very bad years that potentially lie ahead of Iranians.

\section{Unemployment Rate and The Currency Exchange Rate}

Unemployment rate might seem to be rather unrelated to sanctions but It seems rather important to include that in the review as an economic indicator for ordinary people. The unemployment rates and the trends are shown in Figure 6 for youths and for adults over the last 10 years [6]. The exchange rate or the value of Iranian Rial has dropped very badly during 
the last 8 months, which has caused unimaginable problems. Figure 5 demonstrates how chaotic and unstable the value of Rial is [7].

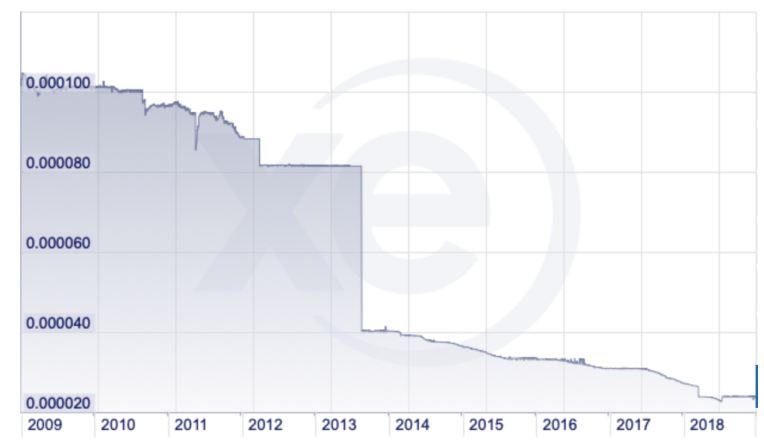

Fig. 5. The Official Value of Rial in USD Since 2009

There seems to be less clear and linear correlation between sanctions and unemployment rates. However, since unemployment originates from economic issues, one could relate the two. The youth unemployment rate is alarmingly high and has increased rapidly in the last few years, which yet again, does not imply a bright future.
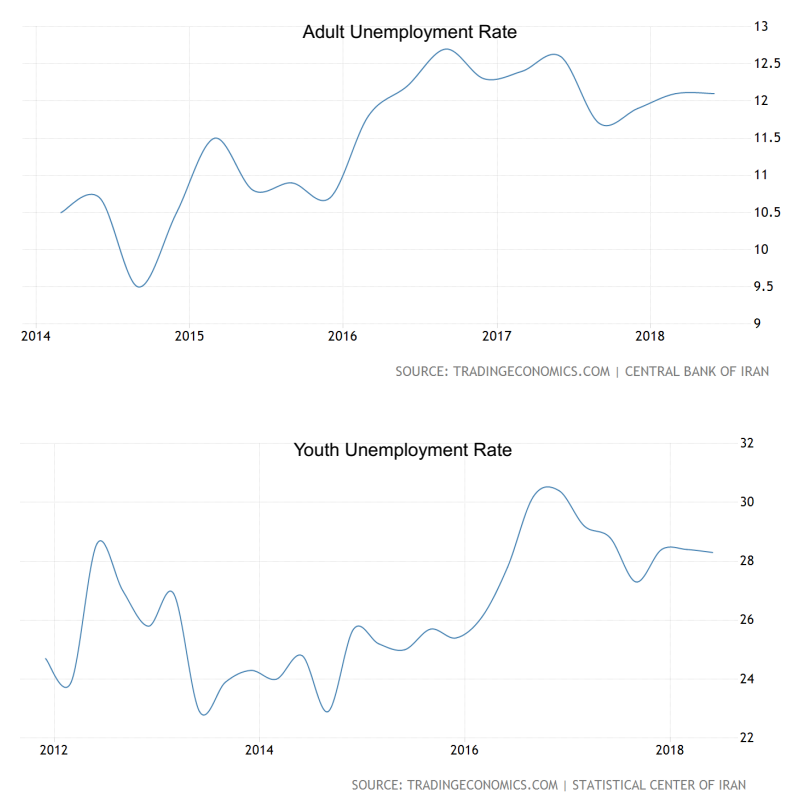

Fig. 6. Iran's Unemployment Rates Over The Last 10 years

\section{E. Conclusion}

The unofficial and market-priced Rial has lost two-thirds of its value in the last 6 months, much of which was after the United States formally withdrew from the nuclear agreement in May. It is clear from the economic factors considered that Iran is about to be isolated again economically, which will decrease trade and prevents Tehran from selling oil unlike the past two years. Unlike two years ago, it was observed that Iran is entering a period of financial difficulty with much less resources than before. Consequences are rather catastrophic for the people on an average income and below, which includes more than 80 percent of individuals who live in Iran based on GDP per capita and the poverty baseline [4], [8]. Hence, questioning the effectiveness of sanctions on Iranian authorities seems to be logical.

\section{Sanctions From A Legal Perspective}

By using UN charter provisions and principles, I have elaborated on the illegitimacy of imposed economic embargoes against Iran. The illegitimacy of such foreign policies by the US then is examined in more detail in two specific cases of human rights and the aviation industry.

\section{A. Legitimacy of economic sanction on Iran}

It is clear that the most important obligation of the UN charter is to preserve international peace and security under Article 24 of the charter, and in accordance with $7^{\text {th }}$ chapter of the charter [9] "the security council shall determine the existence of any threat to the peace, or act of aggression and shall make recommendation, or decide what measures shall be taken in accordance with Articles 41 and 42, to maintain or restore international peace and security."

In recent years, Iran has been targeted by many different sanctions by the U.S for its peaceful nuclear activities, with respect to the fact that achieving peaceful nuclear activities based on NPT is a certain right of states [10]. However, lifting an embargo has severe implications on different sectors of Iran and will stagnate the economy and trade balance. Imposing sanctions in the form of restricting imports and exports contradicts the current economic system founded by the West. In fact, by accepting these terms any violation of their freedom is a violation of their basic rights. Sanctions are not the best way to resolve conflicts but the most effective way to endanger peace. United Nations Conference on Trade and Development (UNCTAD) stated that "These measures do not help to create a peaceful atmosphere, which is necessary for development" in a resolution; they also stated in the resolution titled "rejection of coercive economic measures" that "All developed countries should avoid trade restrictions, blockades, bans on trade and other economic sanctions incompatible with the provisions of the UN Charter against developing countries, as a form of political coercion, which affects the economic and social development of these countries" [9] [10].

\section{B. Human Rights Violation}

The embargo imposed by the U.S produces considerable humanitarian-related implications. For instance, it was reported in 2018 that the re-imposition of sanctions against Iran might inhibit the flow of humanitarian goods to Iranians and contribute to a shortage of medicine to treat ailments due to the evaporation of available transactions financing [2].

Article 2 and 28 of the Universal Declaration of Human Rights accordingly declares that "no distinction shall be made on the basis of the political, jurisdictional or international status of the country or territory to which a person belongs, whether it 
be independent, trust, non-self-governing or under any other limitation of sovereignty and everyone is entitled to a social and international order in which the rights and freedoms set forth in this declaration can be fully realised." Therefore, the basic rights of people should not be threatened under any condition. Many Iranians have a low standard of living and their complications have been escalated by imposed sanctions as briefly demonstrated earlier in the paper as well as in Figures 1 to 6 .

\section{The Aviation Industry in Iran and Safety}

According to re-imposed sanctions, licenses for sales of commercial aircraft was revoked after November 2018. However, based on article 44 of the Chicago convention "the aims and objectives of the organisation are to develop the principles and techniques of international air navigation and to foster the planning and development of international air transport" which is summarised to:

- Ensure the safe and orderly growth of international civil aviation throughout the world;

- Encourage the arts of aircraft; design and operation for peaceful purposes

- Encourage the development of airways, airports, and air navigation facilities for international civil aviation;

- Meet the needs of the world for safe, regular, efficient and economical air transport;

- Prevent economic waste caused by unreasonable competition;

- Ensure that the rights of contracting states are fully respected and that every contracting state has a fair opportunity to operate international airlines;

- Avoid discrimination between contracting states;

- Promote safety of flight in international air navigation;

- Promote generally the development of all aspects of international civil aeronautics." [11]

Sanctions against importation of commercial aircraft and parts to Iran took effect in early August 2018. However, the International Court of Justice in The Hague states that, while some of Irans rights under the treaty might have been affected by the US consideration of national security interests, it views other rights such as those relating to the import of humanitarian goods, or services to ensure civil aviation safety as not being so. Some of these rights, it adds, are such that disregarding them "may entail irreparable consequences", notably if they expose people to threats to health and life. "In [the court's] opinion, the measures adopted by the [USA] have the potential to endanger civil aviation safety in Iran and the lives of its users to the extent that they prevent Iranian airlines from acquiring spare parts and other necessary equipment [or services]," it says. The US government, in line with the 1955 treaty, "must remove" any impediments to the free export of spares, equipment and services necessary to preserve safety of civil aviation. A similar ruling covering the export of medicine and agricultural commodities has also been issued by the primary judicial agency of the United Nations. [12].

\section{CONCLUSION}

A few conclusions could be drawn after spending a couple of pages reviewing sanctions from two different perspective. It is clear from all economic factors that the newly imposed sanctions have already and will hit Iran's economy extremely severely however, this embargo is inconsistent with international cooperation and governments are obliged not to undertake such actions based on [9]. Moreover, sanctions were imposed mainly to restrict Iran's activities in the region yet the budget for Iranian revolutionary guard and army have been increased considerably in the last 12 months [13]. Therefore, despite the intentions behind such sanctions, Iranians seem to be targeted to face economic and social challenges. Economic sanctions should be imposed with legitimacy and proper regulation such that it doesn't threaten civilians in the country. Hence, such actions should be prevented and even criticised heavily by other countries because of its possible adverse impact on international peace and security.

\section{REFERENCES}

[1] Joint comprehensive plan of action. 2015.

[2] Iran sanctions. Congressional Research Service, 2019.

[3] Report on oil independent economy for iran.

[4] World Bank Group. MPO, pages 154-155, 2018.

[5] Iran central bank report, 2010-2017.

[6] Statistical centre of iran annual report, 2010-2018.

[7] Xe official exchange rate.

[8] Poverty in iran by isna - iran students news association.

[9] Article 39 Chapter 5 UN Charter, 2018.

[10] vali golmohammadi and peyman Imani. The legitimacy of economic sanctions against islamic republic of iran in the light of international economic law. MCSER, 7(3):61-71, 2016.

[11] Article 44 of chicago convention.

[12] Fight global webpage.

[13] Iran's 2018-2019 budget detailed report bbc persian. 